\title{
Animal models and therapeutic molecular targets of cancer: utility and limitations
}

This article was published in the following Dove Press journal:

Drug Design, Development and Therapy

14 October 2014

Number of times this article has been viewed

\author{
Maria Cekanova \\ Kusum Rathore \\ Department of Small Animal \\ Clinical Sciences, College of \\ Veterinary Medicine, The \\ University of Tennessee, \\ Knoxville, TN, USA
}

Correspondence: Maria Cekanova Department of Small Animal Clinical Sciences, The University of Tennessee, College of Veterinary Medicine 2407 River Drive AI22, Knoxville, TN 37996-4550, USA

$\mathrm{Tel}+\mathrm{I} 8653895222$

Fax + I 8659745554

Email mcekanov@utk.edu
Abstract: Cancer is the term used to describe over 100 diseases that share several common hallmarks. Despite prevention, early detection, and novel therapies, cancer is still the second leading cause of death in the USA. Successful bench-to-bedside translation of basic scientific findings about cancer into therapeutic interventions for patients depends on the selection of appropriate animal experimental models. Cancer research uses animal and human cancer cell lines in vitro to study biochemical pathways in these cancer cells. In this review, we summarize the important animal models of cancer with focus on their advantages and limitations. Mouse cancer models are well known, and are frequently used for cancer research. Rodent models have revolutionized our ability to study gene and protein functions in vivo and to better understand their molecular pathways and mechanisms. Xenograft and chemically or genetically induced mouse cancers are the most commonly used rodent cancer models. Companion animals with spontaneous neoplasms are still an underexploited tool for making rapid advances in human and veterinary cancer therapies by testing new drugs and delivery systems that have shown promise in vitro and in vivo in mouse models. Companion animals have a relatively high incidence of cancers, with biological behavior, response to therapy, and response to cytotoxic agents similar to those in humans. Shorter overall lifespan and more rapid disease progression are factors contributing to the advantages of a companion animal model. In addition, the current focus is on discovering molecular targets for new therapeutic drugs to improve survival and quality of life in cancer patients.

Keywords: mouse cancer model, companion animal cancer model, dogs, cats, molecular targets

\section{Introduction}

Cancer has been characterized by several hallmarks during its multistep development: sustaining proliferative signaling, evading growth suppressors, enabling replicative immortality, resisting cell death, tumor-promoting inflammation, induction of angiogenesis, activation of invasion and metastasis, genome instability and mutations, avoidance of immune destruction, and deregulation of cellular energetics. ${ }^{1}$ Cancer is the second most common cause of death in the USA, exceeded only by heart disease, according to the American Cancer Society. ${ }^{2}$ In 2014, about 585,720 Americans are expected to die of cancer, with almost 1,600 people per day and about 1,665,540 new cancer cases expected to be diagnosed in 2014. Cancer is usually detected when structural changes in a tissue or organ have occurred. The 5-year relative survival rate for all cancers diagnosed between 2003 and 2009 is 68\%, up from 49\% in 1975-1977. ${ }^{2}$ Early detection of tumors and accurate monitoring of tumor response to treatment are key 
to patient survival. Discovery of tumor-specific molecular targets is required to improve detection and efficient treatment of cancer at earlier stages. Thus, the appropriate use and development of in vitro and in vivo cancer models is highly desirable.

Cancer research uses animal and human cancer cell lines in vitro to study biochemical pathways in cancer cells. ${ }^{3}$ Almost all of the continuous cancer cell lines are derived from high-grade, high-stage cancers. The use of normal cell lines was made possible by immortalization of these cells using viral vectors. ${ }^{4,5}$ On the way to personalized treatment protocols based on an individual's genetic profile, the use of patient-derived primary cancer cell lines instead of generic cell lines has become a valuable in vitro system for developing cancer treatment regimes. ${ }^{6,7}$ The advantages of in vitro cancer models are highly controlled conditions, homogeneity, discovery of molecular mechanisms, and reproducibility. The main limitations of two-dimensional in vitro cell culture cancer cell lines are selection of phenotypic and genotypic cells during adaptation to in vitro conditions, accumulation of mutations in cells over time in culture, a homogeneous population of cells, and isolation of cells from the tumor microenvironment. Mimicking the interactions between tumor cells and the cellular matrix, well defined threedimensional in vitro cancer models and coculture systems have gained acceptance for a wide variety of diagnostic and therapeutic applications. ${ }^{8,9}$ Despite all the mentioned disadvantages, cancer cell lines have been, and will continue to be, the model in vitro system for cancer studies.

The development of in vivo animal models that recapitulate the natural history of human cancers and their clinical response to therapy constitute a major prerequisite for rapid bench-to-bedside translation of investigational anticancer therapies and imaging agents that have shown promise in in vitro models (as shown in Figure 1). This review summarizes the advantages and limitations of in vivo animal cancer models with a focus on xenograft and chemically or genetically induced mouse models of cancer, and spontaneously occurring companion animal cancer models. Spontaneous cancers in companion dogs and cats offer a unique model for human cancer biology and translational cancer therapeutics. ${ }^{10}$ Companion animals have a relatively high incidence of cancers, with biological behavior, response to therapy, and response to cytotoxic agents similar to those occurring in humans. A shorter overall lifespan and more rapid disease progression are further factors contributing to the advantages of a companion animal model. ${ }^{10-12}$ In addition, we discuss the current knowledge about therapeutic targets that play a major role in human and animal tumorigenesis.

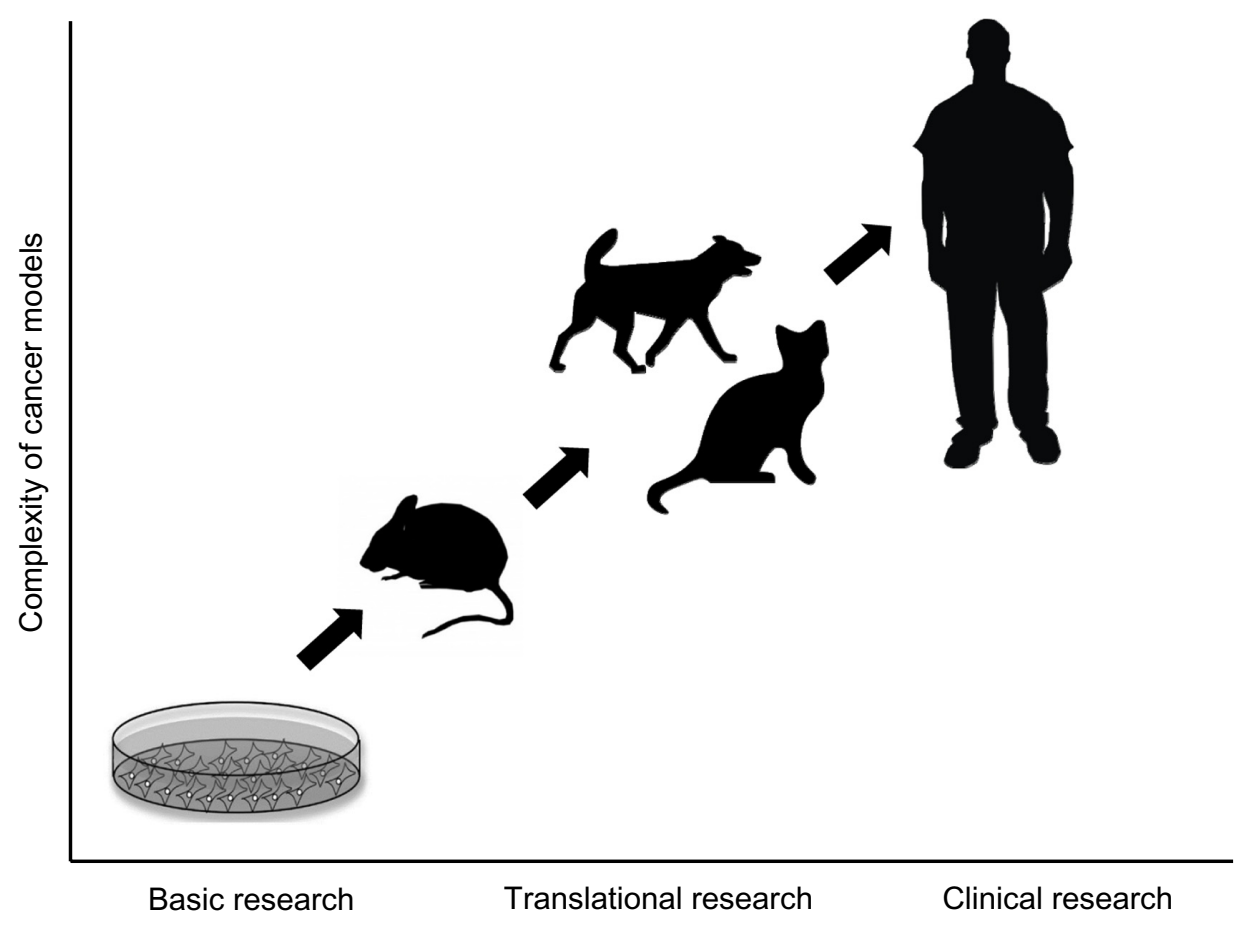

Applications of models during drug discovery for cancer

Figure I Importance of companion animal cancer models during drug discovery for cancer detection and treatment.

Note: Complexity of cancer models ranging from in vitro to in vivo models and correlation with their utility during the novel therapeutic and imaging agents' evaluation. 


\section{Rodent cancer models}

The greatest challenge facing cancer scientists is our incomplete understanding of the genetic basis for complex human diseases, including cancer. Much of the research in human cancer genetics relies on animal models. Mouse cancer models are well known and are frequently used as models for cancer research. Mouse models have revolutionized our ability to study gene and protein function in vivo and to better understand their molecular pathways and mechanisms. ${ }^{13}$ The most common rodent cancer models are xenografts and chemically or genetically induced cancers. ${ }^{14}$

\section{Rodent xenograft cancer model}

In the xenograft cancer model, human or animal cancer cells are transplanted either under the skin (ectopic) or into the organ of tumor origin (orthotopic) using immunocompromised rodents. ${ }^{14-16}$ The most common types of immunocompromised rodents used in cancer research are athymic nude (Forkhead box protein N1 [Foxn1 $\left.{ }^{n u}\right]$ ) mice and severely compromised immunodeficient (SCID) mice. ${ }^{17}$ The athymic nude mouse has a mutation of the Foxn1 gene resulting in a severely compromised immune system. SCID rodents have a single nucleotide polymorphism within the DNA-dependent protein kinase of catalytic polypeptide $(P r k d c)$ gene, resulting in complete failure of their immune system due to absent or atypical $\mathrm{T}$ and $\mathrm{B}$ lymphocytes.

Xenograft animal cancer models are a relatively inexpensive method for generating in vivo tumors using human and animal cancer cell lines. These models enable in vivo testing and development of successful cancer therapy and imaging agents identified in vitro. ${ }^{18,19}$ The major disadvantages of the xenograft rodent cancer models that limit the rapid translation of research to the human clinic include; effectiveness of specific anticancer drugs toward only certain cancer tumors, the superficial vascularization of xenograft tumors, and the lack of stroma-tumor interactions. The major limitation of xenograft cancer models is that the mice and rats used have compromised immune systems, so do not represent the behavior of naturally occurring cancers in humans..$^{18,20}$

\section{Chemically induced rodent models of cancer}

Chemically induced rodent models of cancer are developed by exposure to carcinogens, eg, N-butyl-N-(4-hydroxybutyl) nitrosamine, ${ }^{21-24}$ 4-(methylnitrosamino)-1-(3-pyridyl)-1butanone, ${ }^{25,26} \mathrm{~N}$-ethyl-N-nitrosourea, ${ }^{27}$ azoxymethane, ${ }^{28,29}$ benzopyrene, ${ }^{30}$ urethane, ${ }^{31}$ and asbestos fibers..$^{32}$ Chemically induced cancer rodent models help in the study of the complex traits of cancer, but require high-throughput sequencing to identify the mutations, making the method laborious and time-consuming.

\section{Genetically engineered mouse models of cancer}

In the past, conditional and inducible systems were used to allow tissue-specific and time-specific induction of various oncogenes or suppression of tumor suppressor genes, leading to the development of spontaneous cancers. ${ }^{33}$ The most commonly used systems are Cre-Lox, ${ }^{34}$ tetracycline-dependent promoter regulation, ${ }^{35}$ and Flp-mediated site-specific and spontaneous recombination methods. ${ }^{36}$ Genetically modified mice are created by microinjection of DNA in the pronuclei of fertilized zygotes and the transgene is integrated into the genome. ${ }^{37,38}$ Transgenic mice generated to carry cloned oncogenes $^{39}$ and knockout mice lacking tumor suppressor genes ${ }^{40}$ have provided good models of human cancer. Several transgenic models have been developed for sporadic cancers, eg, via suppression of the $A p c$ gene in an animal model of human familial adenomatous polyposis. ${ }^{41,42}$ Those genetically engineered animal models have had a high impact in oncology drug discovery and preclinical translational biology. ${ }^{31,43-45}$ The major disadvantage of these models is the inability to control the level and pattern of gene expression. Random integration of a transgene can also result in unexpected phenotypes. ${ }^{13}$

\section{Companion animals}

Companion animals with spontaneous neoplasms are still an underexploited approach for making rapid advances in the treatment of human and veterinary cancers by testing new compounds and delivery systems that have shown promise in vitro and in vivo in mouse models. A mouse model has several advantages, including short gestation times, small size, relatively inexpensive maintenance, and easy manipulation of gene expression. ${ }^{46}$ However, the average rate of successful translation from rodent models to clinical cancer trials is less than $8 \%{ }^{47}$ Another major disadvantage of the mouse model is that mice can tolerate higher drug concentrations than human patients, and mouse bone marrow may be less sensitive to many cytotoxic agents. ${ }^{48}$ Considering the vast species differences between mice and humans, it is important to utilize other animal models, such as companion animals with naturally occurring cancers.

Comparative oncology integrates companion animals with naturally occurring cancers to study cancer biology. Clinical trials with companion animals promote advances in humans, 
as well as animal oncology including testing new diagnostics and therapeutics that will benefit both humans and companion animals. In 2014, there will be an estimated 1.6 million human patients diagnosed with cancer in the US. ${ }^{2}$ Roughly 6 million dogs and similar number of cats are diagnosed with cancer each year in the US. This large population of pets with cancer provides the opportunity to study spontaneous cancers similar to those that occur in humans. ${ }^{49}$ Naturally occurring tumors in dogs and cats have more clinical and biological similarities to human cancers than any other animal cancer model. ${ }^{46}$ Dogs develop tumor at twice the frequency of humans, and cats at half the frequency of humans. ${ }^{12}$ The average age of a dog developing a spontaneous cancer is 8.4 years, which corresponds to an average human age of 50 years, suggesting that, as in humans, spontaneous cancers in dogs are influenced by age and the environment. ${ }^{50}$ Companion animal cancers occur in animals with an intact immune system. The tumors are heterogeneous, develop recurrent and drug-resistant disease, and metastasize to distant sites. These tumors capture the essence of human cancer better than any other model system. ${ }^{51}$ Animal tumors are histologically very similar to human cancers, and respond similarly to conventional therapies. The significantly shorter lifecycle involved is a major advantage for performing clinical trials, because it allows more rapid collection of survival data. ${ }^{46}$ The disease-free interval in dogs treated for cancer is 18 months, whereas 7 years are needed to assess treatment outcomes in humans. ${ }^{50}$

High coverage dog genome sequencing has enabled better understanding of the genetics of cancer and allows comparisons in canines and humans. ${ }^{52}$ Recent studies have shown stronger similarities between the canine and human genome as compared with the mouse genome. ${ }^{50}$ The same tumor oncogenes and suppressor genes contribute to development of cancer in humans and dogs. ${ }^{50}$ The sequence homology between human and dog cancer-associated proteins, eg, p53, $\mathrm{Rb}, \mathrm{MDM} 2$, BRCA1, and BRCA2, ${ }^{53,54}$ is similar, as shown in Table 1. A phylogenetic tree of the various cancer-related genes, including $p 53, c-M y c$, cyclooxygenase-2 (COX-2), and $c-K I T$, shows that the dog and cat genes are more similar to human genes than to mouse genes, as shown in Figure 2. There are similarities in the cytogenetic abnormalities in human and canine cancers like fusion of the $A b l$ gene (Abelson tyrosine kinase) to a part of the BCR (breakpoint cluster region) gene, which results in constitutively active $\mathrm{BCR}-\mathrm{Abl}$ tyrosine kinase in leukemia, ${ }^{55}$ or presence of $c$-KIT mutations in gastrointestinal tumors ${ }^{56}$ in humans and canines. Dogs can develop a wide range of cancers, the most common being lymphoma, hemangiosarcoma, osteosarcoma (OSA), mast cell tumors, melanoma, squamous cell carcinoma, mammary carcinoma, apocrine gland carcinoma (anal sac), transitional
Table I List of major molecular targets with their sequence percentage identities to human proteins

\begin{tabular}{llll}
\hline & Mouse (\%) & Cat (\%) & Dog (\%) \\
\hline P53 & 77 & 80 & 79 \\
c-Myc & 91 & 93 & 94 \\
COX-2 & 87 & 90 & 90 \\
c-Kit/CDII7 & 82 & 89 & 88 \\
K-RAS & 97 & 99 & 99 \\
EGFR & 88 & 89 & 89 \\
PDGFR- $\alpha$ & 94 & 91 & 98 \\
$\beta-$ catenin & 99 & 99 & 99 \\
PTEN & 99 & 100 & 100 \\
BRCAI & 56 & 72 & 74 \\
\hline
\end{tabular}

Notes: The sequences identified in various species were compared using the Basic Local Alignment Search Tool from the National Center for Biotechnology Information.

Abbreviations: BRCAI, breast cancer type I susceptibility protein; c-Kit/CDII7, tyrosine-protein kinase Kit/cluster of differentiation II7; c-Myc, cytoplasmicmyelocytomatosis oncoprotein; COX-2, cyclooxygenase-2; EGFR, epidermal growth factor receptor; K-RAS, Kirsten rat sarcoma viral oncoprotein; $\mathrm{p} 53$, tumor suppressor p53; PDGFR- $\alpha$, platelet-derived growth factor receptor- $\alpha$; PTEN, phosphatase and tensin homologue.

cell carcinoma, and soft tissue sarcoma. ${ }^{50,57}$ Several types of cancer that might be suitable models for human cancer, along with the estimated percentage of all new cancers in dogs and cats in the USA, are summarized in Table 2.

\section{Lymphoma}

Lymphomas are lymphocyte cancers that can arise anywhere lymphocytes are found, including the bone marrow, lymph nodes, the spleen, intestines, and other areas of the lymphatic system. Leukemia is a cancer of blood-forming cells arising in the bone marrow. Leukemias and lymphomas are classified according to the type of cell that is exhibiting uncontrolled growth. There are an estimated 731,277 people living with or in remission from lymphoma in the USA, and approximately 79,990 new cases of lymphoma are expected in the USA in $2014 .^{58}$ Lymphomas are among the most common types of tumors in dogs, with the highest incidence of non-Hodgkin lymphoma making up $83 \%$ of all hematopoietic cancers in dogs. ${ }^{59}$ Feline lymphoma accounts for $50 \%-90 \%$ of all hematopoietic tumors in cats, and since hematopoietic tumors represent approximately one third of all feline tumors, it is estimated that 200 per 100,000 cats are at risk. ${ }^{60}$ Feline leukemia virus was the most common cause of lymphoma from 1960 to 1980 , when approximately two thirds of lymphoma cases were associated with feline leukemia virus antigenemia. ${ }^{60}$ The causes of canine lymphoma are mostly genetic, but environmental factors such as herbicides are also suspected. ${ }^{61}$ There are strong similarities between canine and human lymphomas, including cytogenetic and clinical features, tumor biology, tumor behavior, and genetic aberrations, making dogs an important animal model to study disease progression and 
A
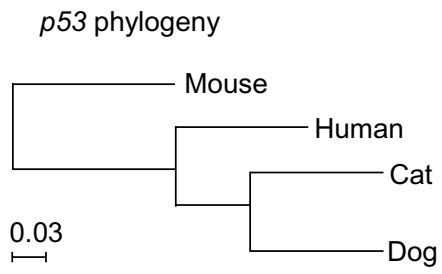

C

COX-2 phylogeny

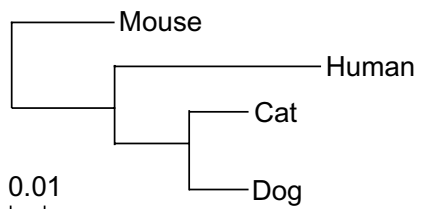

B

c-Myc phylogeny

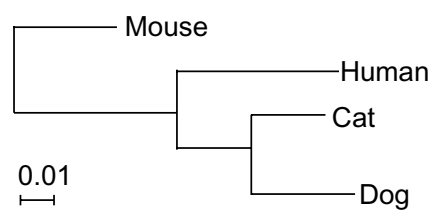

D

c-KIT phylogeny

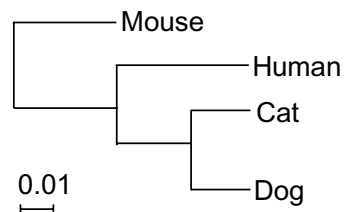

Figure 2 Phylogenic trees of genes for different species.

Notes: Phylogenetic trees of several cancer-related genes. (A) p53, (B) C-Myc, (C) COX-2, and (D) C-KIT/CDII7, show that dog and cat genes are more similar to human genes when compared with those of the mouse. Sequence homology was compared using the Basic Local Alignment Search Tool from the National Center for Biotechnology Information and the phylogenetic trees were constructed based on the COBALT Multiple Sequence Alignment Tool with "neighbor joining" as the tree construction method. Abbreviations: c-KIT/CD I I 7, tyrosine-protein kinase Kit/luster of differentiation I I7; c-Myc, cellular myelocytomatosis oncogene; COX-2, cyclooxygenase-2; p53, tumor suppressor p53.

therapeutic options. ${ }^{46,59}$ The incidence of canine non-Hodgkin lymphoma is similar to that in humans, ${ }^{62}$ with an estimated population of more than 75 million dogs at risk in the USA. ${ }^{63}$ Humans and dogs have similar non-Hodgkin lymphoma histology, with diffuse large B-cells and a similar treatment regimen of combination chemotherapy including cyclophosphamide, doxorubicin, vincristine, and prednisone. ${ }^{64}$ Lymphomas are becoming increasingly resistant to commonly used therapies, so it is important to understand the disease and discover novel therapies in suitable animal models. Canine models have been successfully used to develop new chemotherapeutic strategies, eg, asparaginase. ${ }^{65}$

\section{Head and neck cancers}

Cancers arising from squamous cells that line the moist, mucosal surfaces inside the head and neck are collectively known as head and neck cancers (HNC). Approximately

Table 2 Estimated percentage of all new cancers in dogs and cats in the USA

\begin{tabular}{lll}
\hline Type of cancer & Dogs & Cats \\
\hline Lymphoma & $24 \%^{46}$ & $>30 \%^{60}$ \\
Head and neck carcinoma & $6 \%^{60}$ & $10 \%^{73}$ \\
Bladder cancer & $2 \%^{82}$ & Rare $^{60}$ \\
Osteosarcoma & $5 \%^{86}$ & Rare $^{90}$ \\
Mammary cancer & $3.4 \%^{92}$ & $12 \%^{147}$ \\
Prostate cancer & $0.3 \%-0.6 \%{ }^{148}$ & Rare $^{149}$ \\
Lung cancer & $1 \%{ }^{12}$ & Rare $^{12}$ \\
Melanoma & Relatively common & Rare $^{60}$ \\
\hline
\end{tabular}

42,440 new cases of HNC are expected in 2014. Incidence rates are more than twice as high in men when compared with women. ${ }^{2} \mathrm{HNC}$ is aggressive, locally invasive, and frequently diagnosed late in its development, so current treatment strategies including surgery, radiation, and chemotherapy are often ineffective for HNC. ${ }^{66}$

HNC account for $20 \%$ of all oral malignancies in dogs. ${ }^{67}$ Dogs with HNC have been used as experimental models for evaluation of radiation therapy. ${ }^{12}$ Similar to human HNC caused by tobacco exposure and human papillomavirus infection, HNC in companion animals have also been associated with exposure to environmental tobacco smoke ${ }^{68}$ and canine and feline papillomavirus. ${ }^{69,70} \mathrm{HNC}$ account for $75 \%$ of all oral tumors in cats. ${ }^{71,72}$ The incidence of HNC in cats is similar to that in people, accounting for up to $10 \%$ of all feline cancers. ${ }^{73}$ In cats, the cancer metastasizes to the regional lymph nodes (14.8\%-18\%) and lungs (12\%) later in the course of the disease, and most affected cats are euthanized due to poor quality of life. ${ }^{74,75}$ Second-hand tobacco smoke ${ }^{76}$ and papillomavirus are associated with feline $\mathrm{HNC} .{ }^{70}$ Both feline and canine HNC are locally invasive, with metastasis and local disease recurrence. ${ }^{76}$ Due to the very similar risk factors for oral cancers in humans, dogs, and cats, it is important to study cell lines from companion animals with naturally occurring cancers to better understand human disease. ${ }^{\text {? }}$

\section{Bladder cancer}

Bladder cancer is the fourth most common cancer in men and the eighth most common malignancy in women in the 
USA according to the American Cancer Society. An estimated 74,690 new cases of bladder cancer are expected to occur in 2014 in the USA. An estimated 15,580 bladder cancer-related deaths will also occur in this period. ${ }^{2}$ Precise early detection of tumors and accurate monitoring of tumor response to treatment are key to patient survival. ${ }^{77} \mathrm{Up}$ to $70 \%$ of patients with non-muscle-invasive bladder cancer will develop local recurrence after transurethral resection of the tumor. ${ }^{78,79}$

The histologic and biologic characteristics of bladder cancers in dogs are similar to those of bladder cancers in humans. ${ }^{80-82}$ Compared with humans, transitional cell carcinomas in dogs can be low-grade with a superficial papillary appearance or be high-grade invasive tumors that spread through the bladder wall to lymph nodes and to other organs, predominantly the liver and lung. ${ }^{80,83,84}$ The exact cause of transitional cell carcinoma in dogs is still not known; however, a genetic predisposition, pesticides, insecticides, and second-hand smoke are considered to be major risk factors. ${ }^{80,83,84}$ Bladder cancer in cats is very rare. ${ }^{60}$

One of the examples of using dogs diagnosed with transitional cell carcinoma as a cancer model is for evaluation of novel imaging agents to detect bladder cancer. Specific uptake of fluorocoxib A by primary canine transitional cell carcinoma lines in vitro ${ }^{19}$ as well by naturally occurring transitional cell carcinoma during scoping of dogs has been described. ${ }^{19,85}$

\section{Osteosarcoma}

OSA is the most common type of bone cancer in children and adolescents. There are about 800 new cases of OSA in the USA each year, and about 400 of these are in children and teens. ${ }^{2}$ OSA is the most common primary bone tumor found in dogs. ${ }^{86}$ It accounts for up to $85 \%-98 \%$ of all canine bone tumors, ${ }^{87}$ and $>80 \%$ of reported cases are in the giant and large breeds, including the Rottweiler, Scottish Deerhound, German Shepherd, Doberman, Great Dane, and Greyhound. ${ }^{88}$ The usual treatments for OSA include limb amputation and chemotherapy, with a 1-year survival rate of less than $50 \%$, and $20 \%$ or less surviving 2 years or longer. The major problem is metastasis occurring before limb amputation. Dogs with OSA represent a unique model for the disease in humans due to similar histopathology, clinical presentation, and molecular targets, along with similar metastatic sites and survival rates. ${ }^{87}$ Dogs have been a valuable model of OSA and have been used in clinical trials pioneering limb salvage techniques that are now used in humans. ${ }^{89}$ OSA in cats is rare; however, feline and canine skeletal OSA share similar histologic features, although have different prognostic characteristics. ${ }^{90}$

\section{Breast cancer}

Breast cancer is the second most frequently diagnosed cancer in women. Over 230,000 new cases of invasive breast cancer are expected to be diagnosed in the USA during 2014. ${ }^{2}$ Mammary neoplasms are the most common tumor in unspayed female dogs, representing $52 \%$ of all neoplasms. ${ }^{12}$ Canine mammary tumors are similar to those in humans in many aspects, including hormonal dependence, a metastatic pattern, age, and role of environmental factors in onset of the disease. ${ }^{12} \mathrm{Up}$ to $60 \%$ of human cancers and $45 \%$ of dog breast cancers are estrogen receptor-positive ${ }^{64}$ and early spaying prevents the development of breast cancer in dogs. ${ }^{91,92}$ The most common treatment option for breast cancer in dogs is surgery, and chemotherapy is rarely used. ${ }^{12}$ Mammary tumors are the third most common neoplasia in cats, following lymphoid and skin cancers, with $80 \%-90 \%$ being malignant tumors, most of which are adenocarcinomas. ${ }^{12}$ Only $10 \%$ of feline mammary tumors are estrogen receptor-positive, so spaying has very little effect on recurrence of cancer or survival rates in cats. ${ }^{93}$

\section{Prostate cancer}

Prostate cancer is the most frequently diagnosed cancer in men apart from skin cancer, with over 230,000 estimated new cases diagnosed in 2014 in the USA. ${ }^{2}$ Dogs are the only large mammals other than humans with a significant incidence of spontaneous prostate cancer. ${ }^{94}$ The common occurrence of bone metastases and androgen-independent disease in dogs with prostate cancer represents a model for study of therapies for advanced, hormone-nonresponsive prostate cancers in humans. ${ }^{94}$ Treatment options for prostate cancer include local and systemic therapies, as well as nonsteroidal anti-inflammatory drugs, to improve quality of life. ${ }^{95}$ Very few cases of prostate cancer have been reported in domestic cats, most of which are high-grade carcinomas with lymph node and lung metastases. ${ }^{93}$

\section{Lung cancer}

Lung cancer accounts for most of the cancer deaths in men (28\%) and women (26\%), with over 220,000 estimated new cases in 2014 in the USA. ${ }^{2}$ Dogs and cats rarely develop lung cancer; the total incidence is $1 \%$, with most being adenocarcinomas. ${ }^{12,96}$ Surgical excision remains the primary treatment for lung cancer in dogs. Studies have shown a significant increase in the numbers of malignant respiratory tract tumors in dogs exposed to cigarette smoke, ${ }^{97}$ so dogs can be used to study the effects of environmental factors in carcinogenesis as a epidemiologic model, as well as a diagnostic and therapeutic model of lung cancer. 


\section{Melanoma}

Another type of cancer that is a valuable model for human cancer is canine melanoma. In the USA, it is estimated that in 2014 there will be 43,890 and 32,210 new cases of skin melanoma in men and women, respectively. ${ }^{2}$ Chemotherapy has provided little benefit in patients with melanoma, but development of targeted (proto-oncogene B-Raf, extracellular signal-regulated kinase [ERK], or c-Kit inhibitors) and new immune approaches has radically changed the prognosis. ${ }^{98}$ Unlike genetically engineered models, sporadic canine melanocytic neoplasms share several characteristics with human melanoma, ${ }^{99}$ making dogs a more relevant preclinical model for design of clinical trials. ${ }^{100}$ Canine melanomas rarely arise in sun-exposed sites, and mostly occur in the oral cavity, mimicking human mucosal melanoma. The spectrum of canine melanocytic neoplasia includes benign lesions somewhat analogous to nevi, as well as invasive primary melanoma and widespread metastasis. ${ }^{99}$ Melanoma is common in $\operatorname{dog} s^{60,101,102}$ but rare in cats. ${ }^{60,103}$

\section{Other types of cancer}

In 2014 , it is estimated that there will be approximately 12,000 and 23,380 new cases of human soft tissue and brain cancers, respectively, in the USA. ${ }^{2}$ Soft tissue sarcomas are a heterogeneous population of mesenchymal tumors that comprise $15 \%$ and $7 \%$ of all skin and subcutaneous tumors in dogs and cats, respectively. Hemangiosarcomas, chondrosarcomas, lipomas, brain tumors, and soft tissue sarcomas in dogs are valuable models for human soft tissue cancers. ${ }^{60}$

\section{Molecular markers for detection and treatment of cancer}

Development of tumor-specific molecular imaging and therapeutic drugs is required to improve detection and treatment of cancer at earlier stages. ${ }^{1}$ In contrast with conventional chemotherapy that interferes with all rapidly dividing cells, targeted therapy takes an individualized approach to suppression of tumor cells based on inhibition of the identified tumor-driving signaling pathways. The increased complexity of the interaction between signaling pathways and datasets from various cancer types has led to development of new computational models to predict activity of targeted signaling pathways, responses to therapy, and the prognosis in patients with cancer. ${ }^{104}$

There are several major oncogenic signaling pathways that play a role in tumor growth and progression: receptor tyrosine kinase, ie, growth factor receptors, such as vascular endothelial growth factor receptor (VEGFR), epidermal growth factor receptor (EGFR), platelet-derived growth factor receptor, fibroblast growth factor receptor, c-Met, and insulin-like growth factor 1 receptor; Src; Ras/Raf/ mitogen-activated protein kinase/ERK; phosphatidylinositide 3-kinase; G protein-coupled receptor; pRb; Hedgehog; Wnt- $\beta$-catenin; transforming growth factor- $\beta$; nuclear factor kappa-light-chain-enhancer of activated B cells (NFKB), including its target COX-2; and Notch signaling pathways. ${ }^{105}$ Because those molecules are expressed at high levels in cancers, but not in surrounding normal tissues, they are attractive targets for selective detection and treatment of cancers. Most targeted therapies are either small-molecule drugs or monoclonal antibodies. Candidates for small-molecule drugs are usually identified in drug screens assessing the effects of thousands of test compounds on a specific target.

The first molecular target for targeted cancer therapy was the estrogen receptor in breast cancer. Several drugs have been approved by the US Food and Drug Administration for treatment of estrogen receptor-positive breast cancer, including tamoxifen, fulvestrant, toremifene, and aromatase inhibitors. ${ }^{106}$ The tyrosine kinase receptor (TK) family plays an important role in the regulation of cancer. The EGFR, ${ }^{107}$ $c-K i t$, platelet-derived growth factor receptor- $\alpha / \beta$, Src-family kinases, ${ }^{7,108} \mathrm{PI} 3 \mathrm{~K} /$ protein kinase B (AKT)/mammalian target of rapamycin (mTOR) pathways, ${ }^{109}$ and VEGFR ${ }^{110}$ are commonly overexpressed and are effective molecular targets for treatment of cancer. They are called signal transduction inhibitors, and include imatinib mesylate (TK), dasatinib (TK), nilotinib (TK), trastuzumab (human epidermal growth factor receptor 2 [HER-2]), pertuzumab (HER-2), gefitinib (EGFR), erlotinib (EGFR, other TK), cetuximab (EGFR), vandetanib (VEGFR), and sorafenib (VEGF). ${ }^{11}$ Other targeted therapies modify the function of proteins that regulate gene expression and other cellular functions, such as vorinostat (a histone deacetylase inhibitor). Further targeted therapies induce tumor cell apoptosis, such as bortezomib (proteasome) ) $^{112,113}$ and other groups target the immune system to help destroy cancer cells, such as rituximab (CD20). ${ }^{114,115}$ Another class of targeted therapies includes monoclonal antibodies that deliver toxic molecules to cancer cells specifically, such as ibritumomab (targets $\mathrm{CD} 20^{+}$non-Hodgkin B-cell lymphoma [B-cells NHL] by delivering radioactive 111-indium or 90-yttrium). ${ }^{116}$

Inflammation is a hallmark of cancer and has been shown to play a key role in the initiation and progression of the disease. ${ }^{1}$ Many types of cancer that overexpress EGFR have also been shown to overexpress COX-2, ${ }^{117}$ which is downstream of the NFKB signaling pathway. COX-2 increases in inflammatory and premalignant lesions ${ }^{118-120}$ and is expressed at even higher 
levels in carcinomas. ${ }^{81,121,122}$ Genetic studies in transgenic mice overexpressing COX-2 confirmed increased development of metastatic tumors, ${ }^{123,124}$ and COX-2 ${ }^{-/-}$mice showed decreased development of intestinal and skin tumors. ${ }^{125,126}$ Similarly, when COX-2 activity was shut down pharmacologically by nonsteroidal anti-inflammatory drugs (NSAIDs), the development of mammary carcinomas in tumor-prone transgenic mice was strongly suppressed. ${ }^{127}$ NSAIDs are among the most widely used prescription and nonprescription drugs in the world. ${ }^{128,129}$ Identification of the second isoform of the COX enzyme, COX-2, led to discovery of a new class of COX-2 selective inhibitors, ie, the COXIBs, including rofecoxib, celecoxib, valdecoxib, etoricoxib, and lumiracoxib. ${ }^{128,130}$ The use of radioactively or fluorescently labeled COXIBs as a new class of imaging agents is based on selective uptake by COX-2-expressing neoplastic lesions. ${ }^{26,117,131,132}$

Cancer vaccines and gene therapy are often considered to be targeted therapies, because they interfere with the growth of specific cancer cells, according to the National Cancer Institute. ${ }^{111}$

Targeted therapy has allowed substantial progress in the treatment of cancer and shown promising results in combination with other therapies. ${ }^{133-145}$ Targeted therapy is well tolerated, although a variety of side effects are still commonly observed, including rash, diarrhea, hypertension, hypothyroidism, proteinuria, hepatotoxicity, depigmentation, ocular toxicity, hyperglycemia, and dyslipidemia. ${ }^{146}$

\section{Conclusion}

In this review, several preclinical cancer models are described that could be used for diagnosis, therapy, or prognosis. The focus is on their strengths, weaknesses, utility, and significance during development of novel therapeutic drugs and imaging agents for clinical application. The decision regarding which model of cancer to use depends on the stage of drug discovery (see Figure 1). However, the final proof of concept for efficacy and safety of novel therapeutic and imaging drugs lies in humans. The personalized medicine approach is still in its early stages, but shows the early benefits of selective targeted therapy protocols for individual cancer patients. Further investigations with regard to novel molecular target identification, novel drug development, identification of appropriate patients who might benefit from therapy, timing of drug administration for combined therapies, reducing the side effects of treatment, and better understanding of drug resistance are still needed.

\section{Acknowledgment}

We thank Dr Legendre for critical reviewing of this paper.

\section{Author contributions}

MC designed, acquired and interpreted the data, wrote, and approved the final manuscript, designed figures, and agreed to be accountable for all aspects of the work. KR acquired and interpreted the data, wrote and approved the final manuscript, prepared figures, and also agreed to be accountable for all aspects of the work.

\section{Disclosure}

The authors report no conflicts of interest in this work.

\section{References}

1. Hanahan D, Weinberg RA. Hallmarks of cancer: the next generation. Cell. 2011;144(5):646-674.

2. American Cancer Society. Cancer facts and figures 2014. Available from: http://www.cancer.org/acs/groups/content/@research/documents/ webcontent/acspc-042151.pdf. Accessed April 2, 2014.

3. Masters JR. HeLa cells 50 years on: the good, the bad and the ugly. Nat Rev Cancer. 2002;2(4):315-319.

4. Harris SA, Enger RJ, Riggs BL, Spelsberg TC. Development and characterization of a conditionally immortalized human fetal osteoblastic cell line. J Bone Miner Res. 1995;10(2):178-186.

5. Fichorova RN, Rheinwald JG, Anderson DJ. Generation of papillomavirus-immortalized cell lines from normal human ectocervical, endocervical, and vaginal epithelium that maintain expression of tissue-specific differentiation proteins. Biol Reprod. 1997;57(4): 847-855.

6. Welte Y, Davies C, Schafer R, Regenbrecht CR. Patient derived cell culture and isolation of CD133(+) putative cancer stem cells from melanoma. J Vis Exp. 2013;73:e50200.

7. Rathore K, Alexander M, Cekanova M. Piroxicam inhibits masitinib-induced cyclooxygenase 2 expression in oral squamous cell carcinoma cells in vitro. Transl Res. February 21, 2014. [Epub ahead of print.]

8. Cekanova M, Masi T, Plummer HK 3rd, Majidi M, Fedorocko P, Schuller HM. Pulmonary fibroblasts stimulate the proliferation of cell lines from human lung adenocarcinomas. Anticancer Drugs. 2006;17(7):771-781.

9. Wang C, Tang Z, Zhao Y, Yao R, Li L, Sun W. Three-dimensional in vitro cancer models: a short review. Biofabrication. 2014;6(2):022001.

10. Knapp DW, Waters DJ. Naturally occurring cancer in pet dogs: important models for developing improved cancer therapy for humans. Mol Med Today. 1997;3(1):8-11.

11. Spugnini EP, Porrello A, Citro G, Baldi A. COX-2 overexpression in canine tumors: potential therapeutic targets in oncology. Histol Histopathol. 2005;20(4):1309-1312.

12. MacEwen EG. Spontaneous tumors in dogs and cats: models for the study of cancer biology and treatment. Cancer Metastasis Rev. 1990;9(2):125-136.

13. Cheon DJ, Orsulic S. Mouse models of cancer. Annu Rev Pathol. 2011;6:95-119.

14. Ruggeri BA, Camp F, Miknyoczki S. Animal models of disease: pre-clinical animal models of cancer and their applications and utility in drug discovery. Biochem Pharmacol. 2014;87(1):150-161.

15. Huynh AS, Abrahams DF, Torres MS, Baldwin MK, Gillies RJ, Morse DL. Development of an orthotopic human pancreatic cancer xenograft model using ultrasound guided injection of cells. PLoS One. 2011;6(5):e20330.

16. Bibby MC. Orthotopic models of cancer for preclinical drug evaluation: advantages and disadvantages. Eur J Cancer. 2004;40(6):852-857.

17. Morton CL, Houghton PJ. Establishment of human tumor xenografts in immunodeficient mice. Nat Protoc. 2007;2(2):247-250. 
18. Sharpless NE, Depinho RA. The mighty mouse: genetically engineered mouse models in cancer drug development. Nat Rev Drug Discov. 2006;5(9):741-754.

19. Cekanova M, Uddin MJ, Bartges JW, et al. Molecular imaging of cyclooxygenase-2 in canine transitional cell carcinomas in vitro and in vivo. Cancer Prev Res (Phila). 2013;6(5):466-476.

20. Frese KK, Tuveson DA. Maximizing mouse cancer models. Nat Rev Cancer. 2007;7(9):645-658.

21. Zupancic D, Kreft ME, Romih R. Selective binding of lectins to normal and neoplastic urothelium in rat and mouse bladder carcinogenesis models. Protoplasma. 2014;251(1):49-59.

22. Ogawa K, John MS, De Oliveira ML, et al. Comparison of uroplakin expression during urothelial carcinogenesis induced by $\mathrm{N}$-butylN-(4-hydroxybutyl)nitrosamine in rats and mice. Toxicol Pathol. 1999;27(6):645-651.

23. Becci PJ, Thompson HJ, Strum JM, Brown CC, Sporn MB, Moon RC. N-butyl-N-(4-hydroxybutyl)nitrosamine-induced urinary bladder cancer in C57BL/6 X DBA/2 F1 mice as a useful model for study of chemoprevention of cancer with retinoids. Cancer Res. 1981;41(3):927-932.

24. McCormick DL, Ronan SS, Becci PJ, Moon RC. Influence of total dose and dose schedule on induction of urinary bladder cancer in the mouse by N-butyl-N-(4-hydroxybutyl)nitrosamine. Carcinogenesis. 1981;2(3):251-254.

25. Schuller HM, Cekanova M. NNK-induced hamster lung adenocarcinomas over-express beta2-adrenergic and EGFR signaling pathways. Lung Cancer. 2005;49(1):35-45.

26. Schuller HM, Kabalka G, Smith G, Mereddy A, Akula M, Cekanova M. Detection of overexpressed COX-2 in precancerous lesions of hamster pancreas and lungs by molecular imaging: implications for early diagnosis and prevention. ChemMedChem. 2006;1(6):603-610.

27. Russell WL, Kelly EM, Hunsicker PR, Bangham JW, Maddux SC, Phipps EL. Specific-locus test shows ethylnitrosourea to be the most potent mutagen in the mouse. Proc Natl Acad Sci U SA. 1979;76(11): 5818-5819.

28. Neufert C, Becker C, Neurath MF. An inducible mouse model of colon carcinogenesis for the analysis of sporadic and inflammation-driven tumor progression. Nat Protoc. 2007;2(8):1998-2004.

29. Tanaka T, Kohno H, Suzuki R, Yamada Y, Sugie S, Mori H. A novel inflammation-related mouse colon carcinogenesis model induced by azoxymethane and dextran sodium sulfate. Cancer Sci. 2003;94(11):965-973.

30. Denissenko MF, Pao A, Tang M, Pfeifer GP. Preferential formation of benzo[a]pyrene adducts at lung cancer mutational hotspots in P53. Science. 1996;274(5286):430-432.

31. Cekanova M, Lee SH, Donnell RL, et al. Nonsteroidal anti-inflammatory drug-activated gene-1 expression inhibits urethane-induced pulmonary tumorigenesis in transgenic mice. Cancer Prev Res (Phila). 2009;2(5): 450-458.

32. Barrett JC, Lamb PW, Wiseman RW. Multiple mechanisms for the carcinogenic effects of asbestos and other mineral fibers. Environ Health Perspect. 1989;81:81-89.

33. Singh M, Johnson L. Using genetically engineered mouse models of cancer to aid drug development: an industry perspective. Clin Cancer Res. 2006;12(18):5312-5328.

34. Sauer B. Functional expression of the cre-lox site-specific recombination system in the yeast Saccharomyces cerevisiae. Mol Cell Biol. 1987;7(6):2087-2096.

35. Gossen M, Bujard H. Tight control of gene expression in mammalian cells by tetracycline-responsive promoters. Proc Natl Acad Sci US A. 1992;89(12):5547-5551.

36. Schlake T, Bode J. Use of mutated FLP recognition target (FRT) sites for the exchange of expression cassettes at defined chromosomal loci. Biochemistry. 1994;33(43):12746-12751.

37. Adams JM, Cory S. Transgenic models of tumor development. Science. 1991;254(5035):1161-1167.

38. Dickins RA, McJunkin K, Hernando E, et al. Tissue-specific and reversible RNA interference in transgenic mice. Nat Genet. 2007;39(7): 914-921.
39. Stewart TA, Pattengale PK, Leder P. Spontaneous mammary adenocarcinomas in transgenic mice that carry and express MTV/myc fusion genes. Cell. 1984;38(3):627-637.

40. Jacks T, Fazeli A, Schmitt EM, Bronson RT, Goodell MA, Weinberg RA. Effects of an $\mathrm{Rb}$ mutation in the mouse. Nature. 1992;359(6393):295-300.

41. Fodde R, Edelmann W, Yang K, et al. A targeted chain-termination mutation in the mouse Apc gene results in multiple intestinal tumors. Proc Natl Acad Sci U S A. 1994;91(19):8969-8973.

42. Yamaguchi K, Cekanova M, McEntee MF, et al. Peroxisome proliferator-activated receptor ligand MCC-555 suppresses intestinal polyps in ApcMin/+ mice via extracellular signal-regulated kinase and peroxisome proliferator-activated receptor-dependent pathways. Mol Cancer Ther. 2008;7(9):2779-2787.

43. Hung KE, Maricevich MA, Richard LG, et al. Development of a mouse model for sporadic and metastatic colon tumors and its use in assessing drug treatment. Proc Natl Acad Sci U S A. 2010;107(4): $1565-1570$

44. Coffee EM, Faber AC, Roper J, et al. Concomitant BRAF and PI3K/ mTOR blockade is required for effective treatment of BRAF(V600E) colorectal cancer. Clin Cancer Res. 2013;19(10):2688-2698.

45. Martin ES, Belmont PJ, Sinnamon MJ, et al. Development of a colon cancer GEMM-derived orthotopic transplant model for drug discovery and validation. Clin Cancer Res. 2013;19(11):2929-2940.

46. Rowell JL, McCarthy DO, Alvarez CE. Dog models of naturally occurring cancer. Trends Mol Med. 2011;17(7):380-388.

47. Mak IW, Evaniew N, Ghert M. Lost in translation: animal models and clinical trials in cancer treatment. Am J Transl Res. 2014;6(2):114-118.

48. Teicher BA. In vivo/ex vivo and in situ assays used in cancer research: a brief review. Toxicol Pathol. 2009;37(1):114-122.

49. Mazcko C. Comparative Oncology Program, 2012. Available from: https://ccrod.cancer.gov/confluence/display/CCRCOPWeb/Home. Accessed March 28, 2014.

50. Paoloni M, Khanna C. Translation of new cancer treatments from pet dogs to humans. Nat Rev Cancer. 2008;8(2):147-156.

51. Khanna C, Lindblad-Toh K, Vail D, et al. The dog as a cancer model. Nat Biotechnol. 2006;24(9):1065-1066.

52. Lindblad-Toh K, Wade CM, Mikkelsen TS, et al. Genome sequence, comparative analysis and haplotype structure of the domestic dog. Nature. 2005;438(7069):803-819.

53. Mendoza S, Konishi T, Dernell WS, Withrow SJ, Miller CW. Status of the p53, Rb and MDM2 genes in canine osteosarcoma. Anticancer Res. 1998;18(6a):4449-4453.

54. Rivera P, Melin M, Biagi T, et al. Mammary tumor development in dogs is associated with BRCA1 and BRCA2. Cancer Res. 2009;69(22): 8770-8774.

55. Breen M, Modiano JF. Evolutionarily conserved cytogenetic changes in hematological malignancies of dogs and humans- man and his best friend share more than companionship. Chromosome Res. 2008;16(1):145-154.

56. Gregory-Bryson E, Bartlett E, Kiupel M, Hayes S, Yuzbasiyan-Gurkan V. Canine and human gastrointestinal stromal tumors display similar mutations in c-KIT exon 11. BMC Cancer. 2010;10:559.

57. Porrello A, Cardelli P, Spugnini EP. Oncology of companion animals as a model for humans. an overview of tumor histotypes. J Exp Clin Cancer Res. 2006;25(1):97-105.

58. The Leukemia and Lymphoma Society. Facts 2014. Available from: http://www.1ls.org/content/nationalcontent/resourcecenter/ freeeducationmaterials/generalcancer/pdf/facts.pdf. Accessed April 29, 2014.

59. Marconato L, Gelain ME, Comazzi S. The dog as a possible animal model for human non-Hodgkin lymphoma: a review. Hematol Oncol. 2013;31(1):1-9.

60. Withrow SJ, Vail DM, Page RL, editors. Withrow and MacEwen's Small Animal Clinical Oncology. 5th ed. St Louis, MO, USA: Elsevier; 2012 . 
61. Zahm SH, Blair A. Pesticides and non-Hodgkin's lymphoma. Cancer Res. 1992;52(Suppl 19):5485s-5488s.

62. Hahn KA, Bravo L, Adams WH, Frazier DL. Naturally occurring tumors in dogs as comparative models for cancer therapy research. In Vivo. 1994;8(1):133-143.

63. Vail DM, MacEwen EG. Spontaneously occurring tumors of companion animals as models for human cancer. Cancer Invest. 2000;18(8): 781-792.

64. Hansen K, Khanna C. Spontaneous and genetically engineered animal models; use in preclinical cancer drug development. Eur J Cancer. 2004;40(6):858-880.

65. MacEwen EG, Rosenthal RC, Fox LE, Loar AS, Kurzman ID. Evaluation of L-asparaginase: polyethylene glycol conjugate versus native L-asparaginase combined with chemotherapy. A randomized double-blind study in canine lymphoma. J Vet Intern Med. 1992;6(4): 230-234.

66. Raju B, Ibrahim SO. Pathophysiology of oral cancer in experimental animal models: a review with focus on the role of sympathetic nerves. J Oral Pathol Med. 2011;40(1):1-9.

67. Boria PA, Murry DJ, Bennett PF, et al. Evaluation of cisplatin combined with piroxicam for the treatment of oral malignant melanoma and oral squamous cell carcinoma in dogs. J Am Vet Med Assoc. 2004;224(3):388-394.

68. Reif JS, Bruns C, Lower KS. Cancer of the nasal cavity and paranasal sinuses and exposure to environmental tobacco smoke in pet dogs. Am J Epidemiol. 1998;147(5):488-492.

69. Nicholls PK, Klaunberg BA, Moore RA, et al. Naturally occurring, nonregressing canine oral papillomavirus infection: host immunity, virus characterization, and experimental infection. Virology. 1999;265(2):365-374.

70. O'Neill SH, Newkirk KM, Anis EA, Brahmbhatt R, Frank LA, Kania SA. Detection of human papillomavirus DNA in feline premalignant and invasive squamous cell carcinoma. Vet Dermatol. 2011;22(1):68-74.

71. Martin CK, Dirksen WP, Shu ST, et al. Characterization of bone resorption in novel in vitro and in vivo models of oral squamous cell carcinoma. Oral Oncol. 2012;48(6):491-499.

72. DiBernardi L, Dore M, Davis JA, et al. Study of feline oral squamous cell carcinoma: potential target for cyclooxygenase inhibitor treatment. Prostaglandins Leuk Essent Fatty Acids. 2007;76(4): $245-250$.

73. Stebbins KE, Morse CC, Goldschmidt MH. Feline oral neoplasia: a ten-year survey. Vet Pathol. 1989;26(2):121-128.

74. Poirier VJ, Kaser-Hotz B, Vail DM, Straw RC. Efficacy and toxicity of an accelerated hypofractionated radiation therapy protocol in cats with oral squamous cell carcinoma. Vet Radiol Ultrasound. 2013;54(1): $81-88$.

75. Marretta JJ, Garrett LD, Marretta SM. Feline oral squamous cell carcinoma: an overview. Available from: http://veterinarymedicine. dvm360.com/vetmed/Medicine/Feline-oral-squamous-cell-carcinomaAn-overview/ArticleStandard/Article/detail/433715. Accessed July 8, 2014.

76. Wypij JM. A naturally occurring feline model of head and neck squamous cell carcinoma. Patholog Res Int. 2013;2013:502197.

77. Shapiro A, Gofrit ON, Pizov G, Cohen JK, Maier J. Raman molecular imaging: a novel spectroscopic technique for diagnosis of bladder cancer in urine specimens. Eur Urol. 2011;59(1):106-112.

78. Kurth KH. Diagnosis and treatment of superficial transitional cell carcinoma of the bladder: facts and perspectives. Eur Urol. 1997; 31 Suppl 1:10-19.

79. Allard P, Bernard P, Fradet Y, Tetu B. The early clinical course of primary Ta and $\mathrm{T} 1$ bladder cancer: a proposed prognostic index. Br J Urol. 1998;81(5):692-698.

80. Mohammed SI, Knapp DW, Bostwick DG, et al. Expression of cyclooxygenase-2 (COX-2) in human invasive transitional cell carcinoma (TCC) of the urinary bladder. Cancer Res. 1999;59(22): $5647-5650$
81. Pestili de Almeida EM, Piche C, Sirois J, Dore M. Expression of cyclo-oxygenase-2 in naturally occurring squamous cell carcinomas in dogs. J Histochem Cytochem. 2001;49(7):867-875.

82. Mutsaers AJ, Widmer WR, Knapp DW. Canine transitional cell carcinoma. J Vet Intern Med. 2003;17(2):136-144.

83. Knapp DW, Richardson RC, Chan TC, et al. Piroxicam therapy in 34 dogs with transitional cell carcinoma of the urinary bladder. $J$ Vet Intern Med. 1994;8(4):273-278.

84. Mutsaers AJ, Widmer WR, Knapp DW. Canine transitional cell carcinoma. J Vet Intern Med. 2003;17(2):136-144.

85. Cekanova M, Uddin MJ, Legendre AM, et al. Single-dose safety and pharmacokinetic evaluation of fluorocoxib A: pilot study of novel cyclooxygenase-2-targeted optical imaging agent in a canine model. J Biomed Opt. 2012;17(11):116002.

86. Brodey RS, Riser WH. Canine osteosarcoma - a clinicopathologic study of 194 cases. Clin Orthop Relat Res. 1969;62:54-64.

87. Morello E, Martano M, Buracco P. Biology, diagnosis and treatment of canine appendicular osteosarcoma: similarities and differences with human osteosarcoma. Vet J. 2011;189(3):268-277.

88. Ru G, Terracini B, Glickman LT. Host related risk factors for canine osteosarcoma. Vet J. 1998;156(1):31-39.

89. LaRue SM, Withrow SJ, Powers BE, et al. Limb-sparing treatment for osteosarcoma in dogs. J Am Vet Med Assoc. 1989;195(12): 1734-1744.

90. Dimopoulou M, Kirpensteijn J, Moens H, Kik M. Histologic prognosticators in feline osteosarcoma: a comparison with phenotypically similar canine osteosarcoma. Vet Surg. 2008;37(5): 466-471.

91. Sonnenschein EG, Glickman LT, Goldschmidt MH, McKee LJ. Body conformation, diet, and risk of breast cancer in pet dogs: a case-control study. Am J Epidemiol. 1991;133(7):694-703.

92. American Kennel Club Canine Health Foundation. Determining the best age at which to spay or neuter. Available from: http://www.akcchf. org/canine-health/your-dogs-health/determining-the-best-age-at.html. Accessed February 6, 2014.

93. Morrison WB. Cancer in Dogs and Cats. 1st ed. Baltimore, MD, USA: Williams \& Wilkins; 1998.

94. Leroy BE, Northrup N. Prostate cancer in dogs: comparative and clinical aspects. Vet J. 2009;180(2):149-162.

95. Axiak SM, Bigio A. Canine prostatic carcinoma. Compend Contin Educ Vet. 2012;34(10):E1-E5.

96. Hifumi T, Miyoshi N, Kawaguchi H, Nomura K, Yasuda N. Immunohistochemical detection of proteins associated with multidrug resistance to anti-cancer drugs in canine and feline primary pulmonary carcinoma. J Vet Med Sci. 2010;72(5):665-668.

97. Coggins CR. A minireview of chronic animal inhalation studies with mainstream cigarette smoke. Inhal Toxicol. 2002;14(10):991-1002.

98. Shtivelman E, Davies MA, Hwu P, et al. Pathways and therapeutic targets in melanoma. Oncotarget. 2014;5(7):1701-1752.

99. Simpson RM, Bastian BC, Michael HT, et al. Sporadic naturally occurring melanoma in dogs as a preclinical model for human melanoma. Pigment Cell Melanoma Res. 2014;27(1):37-47.

100. Bergman PJ, McKnight J, Novosad A, et al. Long-term survival of dogs with advanced malignant melanoma after DNA vaccination with xenogeneic human tyrosinase: a phase I trial. Clin Cancer Res. 2003;9(4):1284-1290.

101. Goldschmidt MH. Pigmented lesions of the skin. Clin Dermatol. 1994;12(4):507-514.

102. Modiano JF, Ritt MG, Wojcieszyn J. The molecular basis of canine melanoma: pathogenesis and trends in diagnosis and therapy. $J$ Vet Intern Med. 1999;13(3):163-174.

103. Smith SH, Goldschmidt MH, McManus PM. A comparative review of melanocytic neoplasms. Vet Pathol. 2002;39(6):651-678.

104. Verhaegh W, van Ooijen H, Inda MA, et al. Selection of personalized patient therapy through the use of knowledge-based computational models that identify tumor-driving signal transduction pathways. Cancer Res. 2014;74(11):2936-2945. 
105. Weinberg RA. The Biology of Cancer. 2nd ed. New York, NY, USA; Garland Science, Taylor and Francis Group; 2014.

106. Jaitak V. Drug target strategies in breast cancer treatment: recent developments. Anticancer Agents Med Chem. April 7, 2014. [Epub ahead of print.]

107. Xia W, Lau YK, Zhang HZ, et al. Combination of EGFR, HER-2/neu, and HER-3 is a stronger predictor for the outcome of oral squamous cell carcinoma than any individual family members. Clin Cancer Res. 1999;5(12):4164-4174.

108. Dubreuil P, Letard S, Ciufolini M, et al. Masitinib (AB1010), a potent and selective tyrosine kinase inhibitor targeting KIT. PLoS One. 2009;4(9):e7258.

109. Ciruelos Gil EM. Targeting the PI3K/AKT/mTOR pathway in estrogen receptor-positive breast cancer. Cancer Treat Rev. 2014;40(7): 862-871.

110. Al-Dissi AN, Haines DM, Singh B, Kidney BA. Immunohistochemical expression of vascular endothelial growth factor and vascular endothelial growth factor receptor associated with tumor cell proliferation in canine cutaneous squamous cell carcinomas and trichoepitheliomas. Vet Pathol. 2007;44(6):823-830.

111. National Cancer Institute. 2014. Available from: http://www.cancer. gov. Accessed April 30, 2014.

112. Adams J, Kauffman M. Development of the proteasome inhibitor Velcade (bortezomib). Cancer Invest. 2004;22(2):304-311.

113. Chen D, Frezza M, Schmitt S, Kanwar J, Dou QP. Bortezomib as the first proteasome inhibitor anticancer drug: current status and future perspectives. Curr Cancer Drug Targets. 2011;11(3):239-253.

114. Maloney DG, Grillo-Lopez AJ, White CA, et al. IDEC-C2B8 (rituximab) anti-CD20 monoclonal antibody therapy in patients with relapsed low-grade non-Hodgkin's lymphoma. Blood. 1997;90(6):2188-2195.

115. Scott SD. Rituximab: a new therapeutic monoclonal antibody for non-Hodgkin's lymphoma. Cancer Pract. 1998;6(3):195-197.

116. Milenic DE, Brady ED, Brechbiel MW. Antibody-targeted radiation cancer therapy. Nat Rev Drug Discov. 2004;3(6):488-499.

117. Dannenberg AJ, Lippman SM, Mann JR, Subbaramaiah K, DuBois RN Cyclooxygenase-2 and epidermal growth factor receptor: pharmacologic targets for chemoprevention. J Clin Oncol. 2005;23(2): 254-266.

118. Taketo MM. COX-2 and colon cancer. Inflamm Res. 1998; 47 Suppl 2:S112-S116.

119. Eberhart CE, Coffey RJ, Radhika A, Giardiello FM, Ferrenbach S, DuBois RN. Up-regulation of cyclooxygenase 2 gene expression in human colorectal adenomas and adenocarcinomas. Gastroenterology. 1994;107(4):1183-1188.

120. Abdalla SI, Lao-Sirieix P, Novelli MR, Lovat LB, Sanderson IR, Fitzgerald RC. Gastrin-induced cyclooxygenase-2 expression in Barrett's carcinogenesis. Clin Cancer Res. 2004;10(14):4784-4792.

121. Dannenberg AJ, Subbaramaiah K. Targeting cyclooxygenase-2 in human neoplasia: rationale and promise. Cancer Cell. 2003;4(6):431-436.

122. Fosslien E. Molecular pathology of cyclooxygenase-2 in neoplasia. Ann Clin Lab Sci. 2000;30(1):3-21.

123. Neufang G, Furstenberger G, Heidt M, Marks F, Muller-Decker K. Abnormal differentiation of epidermis in transgenic mice constitutively expressing cyclooxygenase-2 in skin. Proc Natl Acad Sci U S A. 2001;98(13):7629-7634.

124. Liu CH, Chang SH, Narko K, et al. Overexpression of cyclooxygenase-2 is sufficient to induce tumorigenesis in transgenic mice. J Biol Chem. 2001;276(21):18563-18569.

125. Oshima M, Dinchuk JE, Kargman SL, et al. Suppression of intestinal polyposis in Apc delta716 knockout mice by inhibition of cyclooxygenase 2 (COX-2). Cell. 1996;87(5):803-809.

126. Chulada PC, Thompson MB, Mahler JF, et al. Genetic disruption of Ptgs-1, as well as Ptgs-2, reduces intestinal tumorigenesis in Min mice. Cancer Res. 2000;60(17):4705-4708.

127. Basu GD, Pathangey LB, Tinder TL, Lagioia M, Gendler SJ, Mukherjee P. Cyclooxygenase-2 inhibitor induces apoptosis in breast cancer cells in an in vivo model of spontaneous metastatic breast cancer. Mol Cancer Res. 2004;2(11):632-642.
128. Marnett LJ. The COXIB experience: a look in the rearview mirror. Annu Rev Pharmacol Toxicol. 2009;49:265-290.

129. Vane JR. Inhibition of prostaglandin synthesis as a mechanism of action for aspirin-like drugs. Nat New Biol. 1971;231(25):232-235.

130. Talley JJ. Selective inhibitors of cyclooxygenase-2 (COX-2). Prog Med Chem. 1999;36:201-234.

131. Marnett LJ, Kalgutkar AS. Cyclooxygenase 2 inhibitors: discovery, selectivity and the future. Trends Pharmacol Sci. 1999;20(11):465-469.

132. Kuge Y, Katada Y, Shimonaka S, et al. Synthesis and evaluation of radioiodinated cyclooxygenase-2 inhibitors as potential SPECT tracers for cyclooxygenase-2 expression. Nucl Med Biol. 2006;33(1):21-27.

133. Zhang J, Yu J, Sun X, Meng X. Epidermal growth factor receptor tyrosine kinase inhibitors in the treatment of central nerve system metastases from non-small cell lung cancer. Cancer Lett. 2014; 351(1):6-12.

134. Boyd M, Mairs RJ, Cunningham SH, et al. A gene therapy/targeted radiotherapy strategy for radiation cell kill by. J Gene Med. 2001;3(2): 165-172.

135. Boyd M, Mairs RJ, Keith WN, et al. An efficient targeted radiotherapy/ gene therapy strategy utilising human telomerase promoters and radioastatine and harnessing radiation-mediated bystander effects. J Gene Med. 2004;6(8):937-947.

136. Boyd M, Mairs SC, Stevenson K, et al. Transfectant mosaic spheroids: a new model for evaluation of tumour cell killing in targeted radiotherapy and experimental gene therapy. J Gene Med. 2002;4(5):567-576.

137. Cowen RL, Williams KJ, Chinje EC, et al. Hypoxia targeted gene therapy to increase the efficacy of tirapazamine as an adjuvant to radiotherapy: reversing tumor radioresistance and effecting cure. Cancer Res. 2004;64(4):1396-1402.

138. Cunningham S, Boyd M, Brown MM, et al. A gene therapy approach to enhance the targeted radiotherapy of neuroblastoma. Med Pediatr Oncol. 2000;35(6):708-711.

139. Fiveash JB, Gillespie GY, Oliver PG, Zhou T, Belenky ML, Buchsbaum DJ. Enhancement of glioma radiotherapy and chemotherapy response with targeted antibody therapy against death receptor 5. Int J Radiat Oncol Biol Phys. 2008;71(2):507-516.

140. Fullerton NE, Boyd M, Mairs RJ, et al. Combining a targeted radiotherapy and gene therapy approach for adenocarcinoma of prostate. Prostate Cancer Prostatic Dis. 2004;7(4):355-363.

141. Fullerton NE, Mairs RJ, Kirk D, et al. Application of targeted radiotherapy/gene therapy to bladder cancer cell lines. Eur Urol. 2005;47(2):250-256.

142. Trachtenberg J, Weersink RA, Davidson SR, et al. Vascular-targeted photodynamic therapy (padoporfin, WST09) for recurrent prostate cancer after failure of external beam radiotherapy: a study of escalating light doses. BJU Int. 2008;102(5):556-562.

143. Weiss GJ, Bunn PA Jr, Camidge DR. From radiotherapy to targeted therapy: 20 years in the management of non-small-cell lung cancer. Oncology (Williston Park). 2006;20(12):1515-1524.

144. Willett CG, Kozin SV, Duda DG, et al. Combined vascular endothelial growth factor-targeted therapy and radiotherapy for rectal cancer: theory and clinical practice. Semin Oncol. 2006;33(5 Suppl 10): S35-S40.

145. Xu L, Pirollo KF, Chang EH. Tumor-targeted p53-gene therapy enhances the efficacy of conventional chemo/radiotherapy. $J$ Control Release. 2001;74(1-3):115-128.

146. Liu S, Kurzrock R. Toxicity of targeted therapy: implications for response and impact of genetic polymorphisms. Cancer Treat Rev. 2014;40(7):883-891.

147. Merck and Co, Inc. The Merck Veterinary Manual. Whitehouse Station, NJ, USA; 2012.

148. Weaver AD. 15 cases of prostatic-carcinoma in the dog. Vet Rec. 1981;109(4):71-75.

149. Hubbard BS, Vulgamott JC, Liska WD. Prostatic adenocarcinoma in a cat. J Am Vet Med Assoc. 1990;197(11):1493-1494. 


\section{Publish your work in this journal}

Drug Design, Development and Therapy is an international, peerreviewed open-access journal that spans the spectrum of drug design and development through to clinical applications. Clinical outcomes, patient safety, and programs for the development and effective, safe, and sustained use of medicines are a feature of the journal, which

has also been accepted for indexing on PubMed Central. The manuscript management system is completely online and includes a very quick and fair peer-review system, which is all easy to use. Visit http://www.dovepress.com/testimonials.php to read real quotes from published authors.

Submit your manuscript here: http://www.dovepress.com/drug-design-development-and-therapy-journal 